\section{Эволюция методических} рекомендаций по анестезиологореанимационному обеспечению пациентов с новой

\section{коронавирусной инфекцией COVID-19}

\section{Evolution of guidelines on anesthesia and intensive care for patients with COVID-19: Editorial}

\author{
A.M. Ovezov', A.G. Yavorovskiy², K.D. Zybin ${ }^{3}$, \\ E.V. Roitman ${ }^{4}$, A.I. Yaroshetskiy ${ }^{4}$, K.M. Lebedinskii ${ }^{5}$, \\ M.Yu. Kirov6, D.N. Protsenko ${ }^{4,7}$, I.B. Zabolotskikh ${ }^{3,8}$
}

\footnotetext{
${ }^{1}$ Moscow Regional Research and Clinical Institute, Moscow, Russia

2 Sechenov First Moscow State Medical University, Moscow, Russia

${ }^{3}$ Krasnodar regional hospital \#2, Krasnodar, Russia

${ }^{4}$ Pirogov Russian National Research Medical University (RNRMU), Moscow, Russia

${ }^{5}$ North-Western State Medical University named after I.I. Mechnikov, Saint Petersburg, Russia

${ }^{6}$ Northen State Medical University, Arkhangelsk, Russia

${ }^{7}$ Municipal Clinical Hospital No. 40, Moscow, Russia

${ }^{8}$ Kuban State Medical University, Krasnodar, Russia
}

\section{Abstract}

The medical scientific community is constantly looking for possible ways to successfully treat the new coronavirus infection COVID-19. With the accumulation of experience and knowledge on this issue, the Russian Federation of Anesthesiologists and Reanimatologists regularly updates recommendations on anesthesia and intensive care for patients with COVID-19. The current, 4th edition, like the previous ones, has undergone significant changes and clarifications. Important updates have been made in the sections on respiratory therapy, drug therapy, thromboprophylaxis, and the managing patients with concomitant diseases. Optimization vectors for the next edition of the recommendations on anesthesia and intensive care for patients with COVID-19 have been formulated and substantiated.

Медицинское научное сообщество постоянно ищет возможные пути успешного лечения новой коронавирусной инфекции COVID-19. По мере накопления опыта и знаний по данной проблеме Федерация анестезиологов и реаниматологов России регулярно обновляет рекомендации по анестезиолого-реанимационному обеспечению пациентов с новой коронавирусной инфекцией COVID-19. Текущая, 4-я, редакция, как и предыдущие, претерпела значительные изменения и дополнения. Важные уточнения внесены в разделы по респираторной терапии, лекарственной терапии, тромбопрофилактике, особенностям ведения пациентов с сопутствующими заболеваниями.
Keywords: COVID-19, coronavirus, guidelines, anesthesia, intensive care

\ For correspondence: Igor B. Zabolotskikh - Dr. Med. Sci., professor, head of Department of Anesthesiology, Intensive Care and Transfusiology, Kuban State Medical University; Krasnodar; Russia; e-mail: pobeda_zib@mail.ru

¿ For citation: A.M. Ovezov, A.G. Yavorovskiy, K.D. Zybin, E.V. Roitman, A.I. Yaroshetskiy, K.M. Lebedinskii, M.Yu. Kirov, D.N. Protsenko, I.B. Zabolotskikh. Evolution of guidelines on 
Сформулированы и обоснованы векторы оптимизации следующей редакции рекомендаций по анестезиолого-реанимационному обеспечению пациентов с новой коронавирусной инфекцией COVID-19.

Ключевые слова: COVID-19, коронавирус, рекомендации, анестезия, интенсивная терапия

凶 Для корреспонденции: Заболотских Игорь Борисович д-р мед. наук, профессор, заведующий кафедрой анестезиологии, реаниматологии и трансфузиологии ФПК и ППС ФГБОУ ВО КубГМУ МЗ РФ, Краснодар, Россия; e-mail: pobeda_zib@mail.ru

匹 Дляцитирования: А.М. Овезов, А.Г. Яворовский, К.Д. Зыбин, Е.В. Ройтман, А.И. Ярошецкий, К.М. Лебединский, М.Ю. Киров, Д.Н. Проценко, И.Б. Заболотских. Эволюция методических рекомендаций по анестезиологореанимационному обеспечению пациентов с новой коронавирусной инфекцией COVID-19. Вестник интенсивной терапии им. А.И. Салтанова. 2020;3:8-14. DOI: 10.21320/1818-474X-2020-3-8-14

ए Поступила: 28.08 .2020

믄 Принята кпечати: 02.09.2020 anesthesia and intensive care for patients with COVID-19: Editor's note. Annals of Critical Care. 2020;3:8-14. DOI: 10.21320/1818-474X-2020-3-8-14

$๘$ Received: 28.08 .2020

自 Accepted: 02.09.2020
Появление нового опасного вируса SARS-CoV-2, вызывающего тяжелое, порой фатальное течение атипичной пневмонии, вынуждает медицинское научное сообщество активно искать возможные пути успешного лечения новой коронавирусной инфекции (НКИ). По мере накопления опыта и знаний по данной проблеме появляются новые или изменяются старые подходы в ведении пациентов. В данной работе проанализировано, как изменяется вектор анестезиолого-реанимационной помощи пациентам с НКИ COVID-19, а какие позиции остаются неизменными.

Наиболее принципиальные уточнения и дополнения реализованы в третьей и четвертой версиях методических рекомендаций (MP) Федерации анестезиологов и реаниматологов России (ФАР) «Анестезиолого-реанимационное обеспечение пациентов с новой коронавирусной инфекцией COVID-19» $[1,2]$. Уже в третьей версии МР ФАР были сделаны следующие изменения:

- дополнена информация по общей и специфической лабораторной диагностике, инструментальным методам обследования;

- отмечена роль многообразных поражений кожи, которые могут быть ранними признаками коронавирусной инфекции;

- детализирован санитарно-эпидемиологический режим в отделениях анестезиологии, реанимации и интенсивной терапии;
- расширена информация о проведении пациентам с НКИ COVID-19 комплекса сердечно-легочной реанимации в стационаре;

- изменены показания к интубации трахеи;

- выделены и описаны «Селективные сорбционные технологии», «Плазмотехнологии и фильтрационные технологии» с развернутыми комментариями по каждой из них;

- уделено большое внимание лечению пациентов с сопутствующим сахарным диабетом, онкологическими заболеваниями, при нарушениях ритма сердца;

- $\quad$ впервые даны рекомендации по тромбопрофилактике у пациентов с НКИ COVID-19;

- впервые описаны особенности проведения анестезии у пациентов с НКИ COVID-19;

- впервые акцентировано внимание на особенностях течения заболевания и интенсивной терапии у беременных и родильниц.

Четвертая, последняя, версия МР ФАР [2] превзошла предыдущую по объему и новизне информации. Так, в настоящих рекомендациях в отличие от предыдущих был отражен еще ряд важных моментов, перечисленных ниже.

Значительно обновлен раздел «Респираторная терапия». Детально раскрыты алгоритмы пошаговой респираторной поддержки, представленные ранее в Клиниче- 
ских рекомендациях ФАР «Диагностика и интенсивная терапия острого респираторного дистресс-синдрома» и в зарубежных публикациях (Рекомендация 77).

Рекомендовано использование НИВЛ у пациентов с острой дыхательной недостаточностью вследствие HКИ COVID-19 при неэффективности оксигенотерапии (Рекомендация 81).

Впервые рекомендовано как можно раньше начинать применение экстракорпоральной мембранной оксигенации (ЭКМО) у пациентов с НКИ COVID-19 при наличии конкретно прописанных критериев для ее начала, так как это приводит к снижению летальности (Рекомендация 84, новая).

У пациентов с острой дыхательной недостаточностью вследствие НКИ COVID-19 не рекомендовано интубировать трахею и начинать инвазивную ИВЛ только по данным субтотальной инфильтрации легочной ткани при КТ (КТ 3-4) или изолированной гипоксемии тяжелой степени, корригируемой ингаляцией кислорода или НИВЛ (Рекомендация 85, новая).

Отдельно оговорено, что при гиперкапнии $\left(\mathrm{PaCO}_{2}>\right.$ 60 мм рт. ст.) возможно увеличение дыхательного объема (ДО) до 10 мл/кг ИМТ в сочетании с увеличением частоты дыханий максимум до 30 в мин (Рекомендация 87), тогда как в предыдущей версии МР не допускалось ДО более 9 мл/кг ИМТ.

У пациентов с ОРДС вследствие НКИ COVID-19 peкомендовано использовать РЕEР 10-12 см вод. ст. и выше $12 \mathrm{~cm}$ вод. $\mathrm{cm}$. при ожирении и высокорекрутабельных легких (Рекомендация 88).

В комментариях к Рекомендации 91 впервые указаны критерии прекращения использования прон-позиции: увеличение $\mathrm{PaO}_{2} / \mathrm{FiO}_{2}>200$ мм рт. ст. при $\mathrm{PEEP/}$ СРАР < 10 см вод. ст., сохраняющееся в течение более 4 ч после последнего сеанса прон-позиции.

Дополнен раздел «Лекарственная терапия» в соответствии с данными последних РКИ по применению кортикостероидов (Рекомендация 111), ингибиторов АПФ (Рекомендации 112 и 113) и статинов (Рекомендации 114 и 115); исключению из рутинного использования противомалярийных препаратов и лопинавира/ ритонавира; включению рекомендаций по применению новых противовирусных средств (Фавипиравир, Ремдесивир).

Расширены за счет новых рекомендаций сведения об особенностях течения заболевания и интенсивной терапии HКИ COVID-19 при сопутствующей патологии.

- У пациентов с НКИ COVID-19 и хроническим болевым синдромом, постоянно получающих опиоиды, не рекомендуется изменять схему противоболевой терапии (Рекомендация 156, новая).

- Рекомендуется активное наблюдение за пациентами с НКИ COVID-19, получающими опиоиды трансдермально, так как при лихорадке может усиливаться абсорбция препаратов через кожу (Рекомендация 157, новая).

- Пациентам с бронхиальной астмой и ХОБЛ рекомендуется продолжать терапию ингаляционными препаратами, включая ингаляционные ГКС (Рекомендация 164, новая).

- При тяжелом течении/обострении ХОБЛ и бронхиальной астмы, требующих назначения ГКС перорально, рекомендуется продолжить их прием, при этом снизив дозу до минимально эффективной (Рекомендация 165, новая).

- Впервые рекомендуется отказаться от использования небулайзеров или минимизировать их применение, если возможно, даже при тяжелых обострениях БА и ХОБЛ, так как высок риск контаминации воздуха помещения SARS$\mathrm{CoV} 2$ (Рекомендация 166, новая).

Полностью обновлен, расширен и снабжен развернутыми комментариями раздел, посвященный тромбопрофилактике при НКИ COVID-19, например:

- Подчеркнуто, что у всех пациентов с НКИ COVID-19 рекомендуется учитывать факторы риска ВТЭО (оценка по шкалам PADUA, CAPRINI и IMPROVE) (Рекомендация 186, новая). Приведены шкалы оценки риска тромбоэмболических осложнений (Приложение 12).

- Не рекомендуется использовать пороговые значения биомаркеров, таких как повышенный $\mathrm{D}$-димер, в качестве единственной причины, вызывающей эскалацию дозировки антикоагулянтов вне рамок клинического испытания (Pекомендация 188, новая).

- У пациентов с НКИ COVID-19 рекомендуется использовать стандартную профилактическую или лечебную дозу НМГ, а не промежуточные дозы (или повышенную дозу на основе веса пациента, если это не указано в инструкции к препарату) (Рекомендация 190, новая).

- Назначение терапевтических доз антикоагулянтов у пациентов с НКИ COVID-19 рекомендуется рассмотреть у пациентов с признаками гиперкоагуляционной коагулопатии, ключевым лабораторным маркером которой является гиперфибриногенемия (Рекомендация 191, новая).

- Пациентам с НКИ COVID-19 и ВTЭО в анамнезе или с подозрением на наличие ВТЭО, если визуализация в данный момент невозможна, рекомендуется назначать терапевтические дозы антикоагулянтной терапии в соответствии со стандартом лечения для пациентов без COVID-19 (Рекомендация 193, новая).

- У пациентов с НКИ COVID-19 в критическом состоянии (тяжелое и крайне тяжелое течение) не рекомендуется применение антиагрегантов для предотвращения ВТЭО (Рекомендация 194, новая). 
- У пациентов в критическом состоянии (тяжелое и крайне тяжелое течение) с COVID-19 с проксимальным ТГВ или ТЭЛА рекомендуется проводить парентеральную, а не пероральную терапию антикоагулянтами (НМГ или фондапаринукс, но не НФГ) (Рекомендация 199, новая).

- У большинства пациентов с НКИ COVID-19 и острой, объективно подтвержденной ТЭЛА без артериальной гипотензии (АДсист. < 90 мм рт. ст. или снижение АД < 40 мм рт. ст., продолжающееся более 15 мин) не рекомендуется проведение системной тромболитической терапии (Рекомендация 200, новая).

- У пациентов с НКИ COVID-19 и острой, объективно подтвержденной ТЭЛА и артериальной гипотензией или признаками обструктивного шока из-за ТЭЛА, у которых нет высокого риска кровотечений и отсутствует эффект от начальной терапии антикоагулянтами, рекомендуется проведение системной тромболитической терапии (Рекомендация 201, новая).

- У пациентов с НКИ COVID-19 без объективно подтвержденной ВТЭО не рекомендуется использовать системный тромболизис, катетер-направленный тромболизис или тромбэктомию (Рекомендация 202, новая).

- У пациентов с НКИ COVID-19 и рецидивирующим ВТЭО, несмотря на применение стандартных лечебных доз антикоагулянтов (НМГ), рекомендуется увеличить дозу НМГ на 25-30 \% (Рекомендация 203, новая).

- На фоне приема антикоагулянтов рекомендуется оценивать факторы риска геморрагических осложнений у пациентов в критическом состоянии (тяжелое и крайне тяжелое течение) с НКИ COVID-19: возраст > 85 лет, предыдущий эпизод кровотечения, нарушения системы гемостаза (количество тромбоцитов $<50 \times 10^{9} /$ л, врожденные геморрагические нарушения), активное кровотечение любой локализации, неконтролируемая артериальная гипертензия (АДсист. > 180 мм рт. ст. и/или АДдиаст. > 110 мм рт. ст.), острый инсульт (в течение 3 мес.), серьезное повреждение головного или спинного мозга, сахарный диабет, злокачественные опухоли, почечная дисфункция или недостаточность, инвазивные процедуры: за 4 ч до и спустя 12 ч после хирургического вмешательства, люмбальной пункции или эпидуральной анестезии (Рекомендация 204, новая).

- Трансфузионные (СЗП, концентрат тромбоцитов, криопреципитат) и лекарственные средства (концентраты факторов свертывания, ингибиторы фибринолиза, рекомбинантный активированный VII фактор свертывания, концентрат антитромбина) коррекции системы гемостаза пациентам с НКИ COVID-19 назначаются по общим правилам и особенностей при данной патологии не имеют (Рекомендация 205, новая).

Разделы, посвященные особенностям течения заболевания и интенсивной терапии у беременных и родильниц, а также у детей разных возрастных групп не претерпели существенных изменений. Также нет принципиальных различий между версиями МР по разделам «Анестезия у пациентов с НКИ COVID-19», «Лекарственные взаимодействия при анестезиолого-реанимационном обеспечении пациентов с COVID-19», «Формирование перечня лекарственных препаратов и расходных материалов для анестезиолого-реанимационного обеспечения пациентов с НКИ COVID-19», «Профилактика иммобилизационных осложнений пациентов с НКИ COVID-19 в отделении реанимации и интенсивной терапии», достаточно детально отраженных в предыдущей версии МР [3, 4].

\section{Что, на наш взгляд, предстоит обсудить авторам следующей редакции рекомендаций?}

1. Все четыре версии раздела «Респираторная терапия» были основаны на данных небольших обсервационных исследований по проведению респираторной поддержки у пациентов с НКИ COVID-19, данных физиологии и патофизиологии дыхания у пациентов с НКИ COVID-19, а также данных рандомизированных исследований у пациентов с острым респираторным дистресс-синдромом различного генеза и степени тяжести. Учитывая особенности патогенеза и патофизиологии острой дыхательной недостаточности у пациентов с НКИ COVID-19, невозможна полная экстраполяция данных, полученных в «больших» РКИ у пациентов с ОРДС, на созданные протоколы лечения пациентов с НКИ COVID-19.

2. Будущие изменения раздела «Респираторная терапия» должны будут ответить на следующие вопросы, основываясь уже на данных рандомизированных или хорошо спланированных обсервационных исследований:

- критерии начала неинвазивной респираторной поддержки,

- критерии прогноза неудачи неинвазивной вентиляции легких и интубации трахеи,

- величина безопасного дыхательного объема при неинвазивной и инвазивной ИВЛ,

- принципы выбора и величины эффективного и безопасного положительного конечно-респираторного давления (PEEP),

- критерии выбора режима неинвазивной респираторной поддержки,

- критерии для начала проведения экстракорпоральной мембранной оксигенации. 
3. Начиная со второй версии, достаточно много уделено внимания ситуациям, связанным с методами, при которых кровь пациента контактирует с инородными поверхностями большой площади, а значит, требует гипергепаринизации. В последующих версиях МР уместно приводить значения лабораторных соответствующих тестов системы гемостаза - АСТ и АЧТВ, при которых возможно начало и/ или завершение таких процедур, а также кратность этих исследований. Кроме того, уместны указания на частоту и состав выполнения коагулограммы для контроля состояния системы гемостаза в целом на фоне экстракорпоральных методов.

4. Выбор, а точнее подбор антитромботической профилактики до сих пор является в значительной степени эмпирически решаемой задачей. Причина проста - теснейшая связь системы гемостаза с реакциями воспаления, системами иммунитета, комплемента, гемодинамики и др. Поэтому нет и не предвидится изменений в положении о том, что «Оптимальный режим тромбопрофилактики для пациентов с НКИ COVID-19 еще не известен, и все рекомендации могут носить временный характер». Однако эту фразу не следует воспринимать как фатальную и безысходную. Напротив, уже имеющийся опыт продемонстрировал успешные возможности привлечения в комплекс антитромботической терапии препаратов, к которым в силу недостаточности доказательной базы сложилось неоднозначное отношение.

В первую очередь речь идет о низкомолекулярных гепаринах (НМГ). Практически все из них (эноксапарины, парнапарин, бемипарин, далтепарин, надропарины), как в виде оригинальных НМГ, так и в виде дженериков, применяются у пациентов с НКИ COVID-19. Но следует помнить, что НМГ представляют весьма гетерогенную группу препаратов. Соответственно, достижение надежного антитромботического эффекта никак не связано с дозированием по принципу «1 шприц 1 раз в день». Уже очевидно, что подобный подход, якобы обеспечивающий профилактический эффект НМГ, порочен и бесперспективен у пациентов с НКИ COVID-19. Очевидным решением является внедрение в рутинную практику метода контроля адекватности терапии НМГ - определения анти-ф.Ха-активности, что также представляет собой сугубо организационную проблему. При этом надежный антитромботический эффект без значимого увеличения риска геморрагических осложнений достигается при значениях анти-ф.Ха-активности $>$ 0,6 - 0,65 ЕД/мл. Будут ли они достигнуты «одним шприцом 0,4 мл» или для этого потребуется выбрать другую дозу или кратность введения - это также следует указать в последующих версиях МР. Еще раз следует понимать, что «механистический» подход к системе гемостаза не работает, несмотря и вопреки всякой доказательной медицине.
5. Способы введения гепаринов, в первую очередь нефракционированного гепарина (НФГ), также могут различаться. Учитывая спектр локальных и системных эффектов этого вещества, вероятно, уместным будет напоминание о возможности ингаляционного способа введения [5]. При этом рассуждения о бо́льшем риске заражения для персонала из-за формирования в воздухе аэрозолей несостоятельны, поскольку если ингаляция НФГ проводится через небулайзер, встроенный в закрытый контур аппарата ИВЛ, то выдох (по идее) также защищается фильтрами; если же ингаляция НФГ проводится с помощью, например, ультразвуковых ингаляторов, то здесь также нет и не будет условий для того, чтобы выдох пациента содержал бо́льшее количество вируса, чем уже имеется.

6. Уместно вспомнить о так называемых препаратах - альтернативных антикоагулянтах, представляющих собой гепариноиды. Несомненно, что фондапаринукс должен быть сохранен в списке рекомендованных средств. Но имеет смысл дать если не рекомендации, то хотя бы напоминания о других гепариноидах, которые в ряде коморбидных случаев становятся реальной альтернативой собственно гепаринам (например, сулодексид и т. п. при гепарин-индуцированной тромбоцитопении). Также в настоящее время нет сколь-либо единого взгляда на применение препаратов-антиагрегантов. Определенная уместность их использования имеется, но выбор также должен определяться всем спектром эффектов таких средств. Вероятно, следует вновь обратить внимание на дипиридамол. В базе PubMed нами обнаружено девять сообщений об успешном в той или иной степени применении дипиридамола у пациентов с НКИ COVID-19, в особенности у проявивших признаки синдрома Кавасаки.

7. Экстренное лечение образовавшихся (микро)тромбозов возможно препаратами-тромболитиками. Видимо, будет уместно добавить эту рекомендацию с подробным описанием средств, доз, методов введения и контроля в последующие версии МР.

8. Тесная связь систем свертывания крови, иммунитета и комплемента в патогенезе пневмонии при НКИ COVID-19 предполагает если не рекомендацию, то упоминание о возможности применения моноклонального антитела экулизумаб как средства, полностью ингибирующего С5-опосредованную активность терминального комплекса комплемента, имеющего значение при повреждении легких и развитии острого респираторного дистресс-синдрома у пациентов с НКИ COVID-19. С другой стороны, ингибирование комплемента сопровождается снижением активности гемокоагуляционных реакций, опосредованных его участием, участием высокомолекулярного кининогена и трансляцией активности через фактор XII. Однако важнейшим условием эф- 
фективного применения экулизумаба является его использование у пациентов с НКИ COVID-19, начиная с первых дней лечения [6]. А вот «старт» антитромботической профилактики с прямых оральных антикоагулянтов представляется сомнительным. Да, эти препараты ингибируют свои «точки приложения» - фактор Ха и тромбин, но в отличие от гепаринов они не повлияют на компоненты системы гемостаза, которые являются общими с реакциями воспаления или трансмиттерами информации.

9. В четвертой версии МР появились указания на необходимость преемственности антитромботической терапии и ее продлении на срок не менее 35 суток даже после выписки больного из стационара. Данная рекомендация должна сохраниться и быть представлена в более развернутом варианте, даже несмотря на то что МР написаны для анестезиологов-реаниматологов.

Несомненно, по своей структуре данные МР ФАР (4-я версия) полностью соответствуют текущим требованиям МЗ РФ и являются документом, обобщающим наиболее актуальную информацию по данной проблеме и определяющим современные стандарты диагностики и ведения пациентов с HКИ COVID-19, с указанием уровней доказательности и убедительности разработанных рекомендаций. Неслучайно в опубликованной Министерством здравоохранения Российской Федерации восьмой версии «Временных методических рекомендаций “Профилактика, диагностика и лечение новой коронавирусной инфекции (COVID-19) ”» от 3 сентября указано: «В целом анестезиолого-реанимационное обеспечение пациентов с новой коронавирусной инфекцией COVID-19 рекомендуется проводить в соответствии c Методическими рекомендациями Общероссийской общественной организации «Федерация анестезиологов и реаниматологов» (http://far.org.ru/newsfar/496metreccovid19).» (c. 76) [7].

\section{ORCID авторов}

Овезов А.М. - 0000-0001-7629-6280

Яворовский А.Г. - 0000-0001-5103-0304

Зыбин К.Д. - 0000-0003-3571-986X

Ройтман Е.В. - 0000-0002-3015-9317

Ярошецкий А.И. - 0000-0002-1484-092Х

Лебединский К.М. - 0000-0002-5752-4812

Киров М.Ю. - 0000-0002-4375-3374

Проценко Д.Н. - 0000-0002-5166-3280

Заболотских И.Б. - 0000-0002-3623-2546

\section{Литература/References}

[1] Анестезиолого-реанимационное обеспечение пациентов с новой коронавирусной инфекцией COVID-19. Методические рекомендации Общероссийской общественной организации «Федерация анестезиологов и реаниматологов». Версия 3. Режим доступа: http://webmed.irkutsk.ru/doc/pdf/covid19far.pdf [Anesthetic and resuscitation services for patients with the new coronavirus infection COVID-19. Methodical recommendations of the All-Russian public organization "Federation of Anesthesiologists and Reanimatologists". Version 3. Access mode: http://webmed.irkutsk.ru/doc/pdf/covid19far.pdf (In Russ)]

[2] Заболотских И.Б., Киров М.Ю., Лебединский К.М. и др. Анестезиолого-реанимационное обеспечение пациентов с новой коронавирусной инфекцией COVID-19. Методические рекомендации Общероссийской общественной организации «Федерация анестезиологов и реаниматологов». Вестник интенсивной терапии им. А.И. Салтанова. 2020; S1: 9-120. DOI: 10.21320/1818-474X-2020-S1-9-120 [Zabolotskikh I.B., Kirov M.Yu., Lebedinskii K.M., et al. Anesthesia and intensive care for patients with COVID-19. Russian Federation of anesthesiologists and reanimatologists guidelines. Annals of Critical Care. 2020; S1: 9-120. (In Russ)]

[3] Анестезиолого-реанимационное обеспечение пациентов с новой коронавирусной инфекцией COVID-19. Методические рекомендации Общероссийской общественной организации «Федерация анестезиологов и реаниматологов». Версия 1. Режим доступа: http://far.org.ru/newsfar/489metreccovid090420 [Anesthetic and resuscitation services for patients with the new coronavirus infection COVID-19. Methodical recommendations of the All-Russian public organization "Federation of Anesthesiologists and Reanimatologists". Version 1. Access mode: http://far.org.ru/newsfar/489metreccovid090420 (In Russ)]

[4] Анестезиолого-реанимационное обеспечение пациентов с новой коронавирусной инфекцией COVID-19. Методические рекомендации Общероссийской общественной организации «Федерация анестезиологов и реаниматологов». Версия 2. Режим доступа: http://far.org.ru/newsfar/493metreccovid19-2 [Anesthetic and resuscitation services for patients with the new coronavirus infection COVID-19. Methodical recommendations of the All-Russian public organization "Federation of Anesthesiologists and Reanimatologists". Version 2. Access mode: http://far.org.ru/newsfar/493-metreccovid19-2 (In Russ)]

[5] Воробьева Н.А., Ройтман Е.В., Мельничук Е.Ю. Ингаляции гепарина у пациентов с новой коронавирусной инфекцией (обзор литературы). Тромбоз, гемостаз и реология. 2020; 2 19-26. DOI: 10.25555/THR.2020.2.0914 [Vorobyeva N.A., E.V. Roitman, E.Yu. Melnichuk Heparin inhalation in patients with new coronavirus infection (review). Tromboz, Gemostaz i Reologia. 2020; 2: 19-26. (In Russ)]

[6] Кудлай Д.А., Бакиров Б.А., Павлов В.Н. Природа моноклонального антитела экулизумаб и его потенциал в отношении коронавирусной инфекции COVID-19. Тромбоз, гемостаз и реология. 2020; 2: 27-32. DOI: 10.25555/ 
THR.2020.2.0915 [Kudlay D A., Bakirov B.A., Pavlov V.N. The nature of eculizumab monoclonal antibody and its potential against coronavirus infection COVID-19. Tromboz, Gemostaz i Reologia. 2020; 2: 19-26. (In Russ)]

[7] Временные методические рекомендации «Профилактика, диагностика и лечение новой коронавирусной инфекции (COVID-19)». Версия 8 (03.09.2020). Режим доступа: https://static-0.minzdrav.gov.ru/system/attachments/ attaches/000/051/777/original/030902020_COVID-19_v8.pdf [Interim guidelines "Prevention, diagnosis and treatment of new coronavirus infection (COVID-19) ". Version 8 (03.09.2020). Access mode: https://static-0.minzdrav.gov.ru/system/attachments/ attaches/000/051/777/original/030902020_COVID-19_v8.pdf (In Russ)] 